\title{
Association of TP53 Mutations With Stem Cell-Like Gene Expression and Survival of Patients With Hepatocellular Carcinoma
}

\author{
HYUN GOO WOO,*,‡ XIN WEI WANG,,$^{\S}$ ANURADHA BUDHU, ${ }^{\S}$ YUN HEE KIM, ${ }^{\ddagger}$ SO MEE KWON, ${ }^{\ddagger}$ ZHAO-YOU TANG," \\ ZONGTANG SUN," CURTIS C. HARRIS, ${ }^{\S}$ and SNORRI S. THORGEIRSSON* \\ *Laboratory of Experimental Carcinogenesis, Center for Cancer Research, National Cancer Institute, National Institutes of Health, Bethesda, Maryland; ${ }^{\ddagger}$ Department of \\ Physiology, Ajou University School of Medicine, Suwon, Korea; 'Laboratory of Human Carcinogenesis, Center for Cancer Research, National Cancer Institute, \\ National Institutes of Health, Bethesda, Maryland; "Liver Cancer Institute and Zhongshan Hospital, Fudan University, Shanghai, China; and "National Laboratory of \\ Molecular Oncology, Cancer Institute, Chinese Academy of Medical Sciences, Beijing, China
}

BACKGROUND \& AIMS: Mutations in TP53, a tumor suppressor gene, are associated with prognosis of many cancers. However, the prognostic values of TP53 mutation sites are not known for patients with hepatocellular carcinoma (HCC) because of heterogeneity in their geographic and etiologic backgrounds. METHODS: TP53 mutations were investigated in a total of 409 HCC patients, including Chinese $(\mathrm{n}=336)$ and white $(\mathrm{n}=73)$ patients, using the direct sequencing method. RESULTS: A total of 125 TP53 mutations were found in Chinese patients with HCC (37.2\%). HCC patients with TP53 mutations had a shorter overall survival time compared with patients with wild-type TP53 (hazard ratio [HR], 1.86; 95\% confidence interval [CI]: 1.37-2.52; $P<.001$ ). The hot spot mutations R249S and V157F were significantly associated with worse prognosis in univariate (HR, 2.11; 95\% CI: $1.51-2.94 ; P<.001)$ and multivariate analyses (HR, 1.79; 95\% CI: $1.29-2.51 ; P<.001)$. Gene expression analysis revealed the existence of stem cell-like traits in tumors with TP53 mutations. These findings were validated in breast and lung tumor samples with TP53 mutations. CONCLUSIONS: TP53 mutations, particularly the hot spot mutations R249S and V157F, are associated with poor prognosis for patients with HCC. The acquisition of stem cell-like gene expression traits might contribute to the aggressive behavior of tumors with TP53 mutation.

Keywords: Liver Cancer; p53; Gene Expression Patterns; Cancer Stem Cells.

$\mathrm{H}$ epatocellular carcinoma (HCC) is one of the most common cancers with dismal clinical outcome accounting for the third highest cause of cancer-related deaths worldwide. ${ }^{1}$ Significantly, China alone accounts for more than $55 \%$ of liver cancer in the world, ${ }^{1}$ and the incidence of HCC continues to increase in the United States and Western Europe. ${ }^{2}$ In addition, the clinical heterogeneity of HCC and the lack of good diagnostic markers and treatment options have rendered this disease a major health problem.

TP53 is a multifunctional transcription factor that, along with number of other functions, regulates genes involved in cell cycle arrest, apoptosis, and senescence in response to various types of stress. Mutations of TP53 are frequently found in human cancers and are generally associated with poor prognosis. In HCC, several studies have shown the association of TP53 mutations with poor survival. ${ }^{3-5}$ However, these studies were limited to specific populations with small sample size. In addition, overwhelming evidence demonstrated multifactorial association of TP53 mutation spectra with environmental and etiologic factors, resulting in variations among geographic regions and racial and ethnic groups. ${ }^{6,7}$ In particular, the mutation at codon 249 position (R249S) is prevalent in China and sub-Saharan Africa. ${ }^{8}$ This site preference is known to associate with the dietary exposure to aflatoxin B1 and hepatitis B virus (HBV) infection. ${ }^{9}$ Therefore, the prognostic value of TP53 mutations needs to be evaluated in the context of such confounding factors. Furthermore, TP53 mutations in different structural and functional regions of TP53 are associated with different prognostic values in diverse cancer types. ${ }^{10-12}$ However, the prognostic values of the different sites of TP53 mutations in HCC have not yet been rigorously evaluated.

In this study, we investigated the prognostic significance of the TP53 mutations in a Chinese cohort of HCC patients and evaluated the impact of individual mutations on prognosis. We found that hot spot mutations at codons 249 and 157 are significantly associated with patients' survival. Additionally, we demonstrated that the TP53 mutated tumors express "stemness"-related genes suggesting a potential progenitor cell origin. These results have both biologic and clinical implications for TP53 mutated HCC.

\footnotetext{
Abbreviations used in this paper: AFP, alpha-feto protein; cDNA, complimentary DNA; Cl, confidence interval; ES, embryonic stem; HB, hepatoblast; HB_DOWN, hepatoblast downregulated genes; HB_UP, hepatoblast over-expressed genes; HBV, hepatitis B virus; HCC, hepatocellular carcinoma; HR, hazards ratio; PCR, polymerase chain reaction.

(1) 2011 by the AGA Institute $0016-5085 / \$ 36.00$

doi:10.1053/j.gastro.2010.11.034
} 


\section{Materials and Methods}

\section{Direct Sequencing of TP53}

A total of 409 HCC patients including 336 Chinese patients collected from Qidong $(\mathrm{n}=120)$ and Shanghai $(\mathrm{n}=216)$ areas and 73 white patients from Belgium $(\mathrm{n}=47)$ and United States $(\mathrm{n}=26)$ were analyzed. Direct sequencing of TP53 exons 5 through 8 was performed using complimentary DNA (cDNA) obtained from frozen tissue specimens by reverse transcription polymerase chain reaction (PCR). Genomic DNAs were used in cases where cDNA samples were not available. Sequencing reaction was performed using $A B I$ 3130xl Genetic Analyzer with BigDye terminator sequencing reaction kit version 1.1 (Applied Biosystems, Carlsbad, CA). The primers for sequencing reaction and PCR are summarized in Supplementary Table 1.

\section{Compiling Gene Expression Data Sets}

Gene expression data sets from the Laboratory of Experimental Carcinogenesis (GSE1898 and GSE4024), GSE5975, ${ }^{13}$ and a publicly available data E-TABM-36 ${ }^{14}$ were complied together. For each data set, average expression levels of each array and gene were set to 0 , and each array was scaled to have standard deviation 1. For multiple tagged gene features for the same Entrez Gene identifier, the gene feature with the highest magnitude (ie, sum of square of each sample) was used as a representative gene feature. Nontumor samples or the samples without TP53 mutations were excluded, and, finally, 366 HCC profiles were compiled. For external validation, breast cancer data (GSE3494, $\mathrm{n}=251)^{15}$ with 2 platforms (HGU-133A and HGU-133B) of Affymetrix (Santa Clara, CA) and a compiled lung cancer data set of GSE11969 ( $\mathrm{n}=149)^{16}$ and GSE8569 $(\mathrm{n}=69)$ were used. Preprocessing of each data set was performed by the same method as described above.

\section{Enrichment of Gene Expression Signatures}

The enrichment of gene sets in individual tumors was determined as described previously. ${ }^{17}$ Briefly, for each array, we assessed the fraction of up- or down-regulated genes with a fold difference greater than 2 in each tested gene set. The gene set enrichment was calculated by hypergeometric test with a threshold of $P<.01$ for significant enrichment. The enrichment scores $S_{\text {up }}$ and $S_{\text {down }}$ for a given signature were calculated as $-\log _{10}$ $(P$ value) from up- and down-regulated gene sets, respectively. The enrichment score $S$ was defined as $S_{u p}$ if $S_{u p}>$ $S_{\text {down }}$ and $S_{\text {down }}$ if $S_{\text {up }}<S_{\text {down }}$. The enrichment patterns across groups were determined by calculating fraction of the significantly enriched samples in a group, and the significance of the group enrichment was calculated by hypergeometric test.

Embryonic stem (ES) cell-related signatures (ie, ES1, ES2, NOS, NOS_TF, and the target genes for Nanog, Oct4, Sox2, Myc1, and Myc2) and proliferation-related gene signature (prol) were obtained from the previous publication site. ${ }^{17}$ NOS includes the target genes for Nanog, Oct4, and Sox2. NOS_TF includes a subset of NOS activation targets encoding transcription regulators. We also obtained rat hepatoblast (HB) gene signatures $(\mathrm{n}=191)$, which contained over-expressed (HB_UP) and down-regulated (HB_DOWN) genes in early fetal liver development. ${ }^{18}$ For the validation using breast and lung cancer data, Gene Set Enrichment Analysis (version 2.0) was applied with default parameters. ${ }^{19}$

\section{Real-Time Quantitative PCR}

The same amount of first-strand cDNA from each sample was used to detect the messenger RNA expression levels using specific primers (CD24 sense $5^{\prime}$ ACAGCCAGTCTCTTCGTGGT-3', antisense 5' -CCTGTTTTTCCTTGCCACAT-3'; alpha-feto protein $(A F P)$ sense 5'-AGCTTGGTGGTGGATGAAAC-3', antisense 5' -CCCTCTTCAGCAAAGCAGAC-3'; glyceraldehyde-3-phosphate dehydrogenase sense 5'-ACCCAGAAGACTGTGGATGG3', antisense 5'-TTCTAGACGGCAGGTCAGGT-3'). PCR was carried out with a SYBR Green Master Mix (Applied Biosystems, Foster City, CA) of 40 cycles for 10 minutes at $95^{\circ} \mathrm{C}, 15$ seconds at $95^{\circ} \mathrm{C}, 30$ seconds at $60^{\circ} \mathrm{C}$, with a final dissociation step of 15 seconds at $95^{\circ} \mathrm{C}, 20$ seconds at $60^{\circ} \mathrm{C}, 15$ seconds at $95^{\circ} \mathrm{C}$ using $\mathrm{ABI} 7000$ real-time PCR system (Applied Biosystems). Each sample was assayed in duplicate, and a control normal liver DNA was included in every assay. The messenger RNA expression levels were normalized with that of the glyceraldebyde-3phosphate debydrogenase, and the relative values compared with a normal liver sample were calculated $(-\Delta \Delta \mathrm{CT})$.

\section{Statistical Analysis}

Survival analysis was performed by Kaplan-Meier method and log-rank test. The association of clinical features with TP53 mutations was analyzed by Fisher exact test. Univariate and multivariate analyses for survival data were performed by using Cox proportional hazard models. Quantitative PCR result was analyzed by Mann-Whitney $U$ test.

\section{Results}

\section{Profiling of TP53 Mutation Status in HCC}

A total of 134 mutations were found in 409 HCC patients (Supplementary Table 2). Of these, 1 case of silent mutation, 2 cases of nonsynonymous single nucleotide polymorphism (R213R), and 1 case of a deletion at splicing site were excluded from the analysis. For tumors with more than 1 mutation, the mutations were counted as a single event. In the Chinese cohort $(\mathrm{n}=334), 125$ cases of TP53 mutations (37.4\%) including missense (120 cases), 4 nonsense, and 1 frame shift mutations were found. The patients from Qidong showed higher mutation rate compared with the patients from Shanghai 
Table 1. Univariate Analysis for Selected Clinical Features of HCC

\begin{tabular}{|c|c|c|c|c|c|}
\hline & Number of patients & Hazard ratio & 95\% Cl lower & 95\% Cl upper & $P$ value \\
\hline \multicolumn{6}{|l|}{ Mutation, any type } \\
\hline Sex (male/female) & $282 / 48$ & 1.23 & 0.78 & 1.93 & .369 \\
\hline Age $(<50 / \geq 50, y)$ & $173 / 157$ & 1.30 & 0.95 & 1.76 & .097 \\
\hline AFP $(\geq 300 /<300 \mathrm{ng} / \mathrm{mL})$ & $170 / 152$ & 2.13 & 1.54 & 2.95 & $<.001$ \\
\hline Size $(\geq /<5 \mathrm{~cm})$ & $177 / 152$ & 1.94 & 1.41 & 2.66 & $<.001$ \\
\hline Presence of cirrhosis (yes/no) & $249 / 80$ & 0.79 & 0.57 & 1.11 & .182 \\
\hline Grade (III, IV/I, II) & $184 / 108$ & 1.82 & 1.28 & 2.58 & $<.001$ \\
\hline $\operatorname{HBV}(+/-)$ & $296 / 38$ & 0.60 & 0.38 & 0.93 & .022 \\
\hline $\operatorname{HCV}(+/-)$ & $5 / 329$ & 0.35 & 0.05 & 2.48 & .269 \\
\hline \multicolumn{6}{|l|}{ TP53 mutation types } \\
\hline Any types & $125 / 209$ & 1.86 & 1.37 & 2.53 & $<.001$ \\
\hline R249S & $77 / 209^{a}$ & 1.98 & 1.41 & 2.80 & $<.001$ \\
\hline V157F & $8 / 209^{a}$ & 4.25 & 1.95 & 9.27 & $<.001$ \\
\hline Hot spot mutations & $84 / 209$ & 2.11 & 1.51 & 2.94 & $<.001$ \\
\hline Non-hot spot mutations & $41 / 209$ & 1.44 & 0.89 & 2.31 & .134 \\
\hline
\end{tabular}

ane case of double mutation with R249S and V157F was counted as a separate event.

areas (54.1\% and $28.0 \%$, respectively). In accordance with previous studies, ${ }^{6,20}$ codon 249 of TP53 (R249S) was the most common mutation $(24.4 \%, 77$ cases) both in the samples from Qidong (36.6\%, 44 cases) and Shanghai (14.4\%, 31 cases). Codon 157 (V157F) was the second most common mutation site $(2.4 \%, 8$ cases), particularly in Qidong province $(7$ cases). By contrast, white HCC patients showed low mutation rate $(7.0 \%, 5$ out of 71$)$ with mutations at codon 249 (3 cases) and codon 157 (2 cases).

\section{Clinicopathologic Features Related to TP53 Mutation Status}

Because of the very high heterogeneity between the mutation status of Chinese and white people, which could introduce bias, survival analysis was confined to the Chinese cohort. The survival data were available in a total of 329 out of the 334 Chinese patients. Follow-up time was truncated to 5 years after surgical resection. Univariate Cox regression analysis was performed to characterize the prognostic association of clinicopathologic features. Of the clinical features, serum AFP $(>300$ $\mathrm{ng} / \mathrm{mL}$ ), tumor size $(>5 \mathrm{~cm})$, and tumor grade ( $>$ III, IV) were significantly associated with the increased risk of death $(P<.001$, Table 1$)$.

Kaplan-Meier plot analysis showed that the presence of TP53 mutations is significantly associated with shorter overall survival (hazard ratio [HR], 1.86; 95\% confidence interval $[\mathrm{CI}]: 1.37-2.52 ; P<.001$ ) (Figure $1 A$ ). Interestingly, when we examined the prognostic values of individual mutations, we found that highly frequent mutations, ie, hot spot mutations (mutation rate $>2 \%$ ), at codon 249 and codon 157 are significantly associated with worse survival (HR, 1.98; 95\% CI: 1.41-2.80; $P=$ $7.1 \times 10^{-5} ; \mathrm{HR}, 4.25 ; 95 \%$ CI: 1.97-9.27; $P<.001$, respectively) (Figure $1 B$ ). Grouping the patients with hot spot mutations $(84 / 125,67.2 \%$ cases with mutations) also showed shorter survival than patients with the wildtype TP53 $(P<.001)$ (Figure $1 C)$. Multivariate analysis
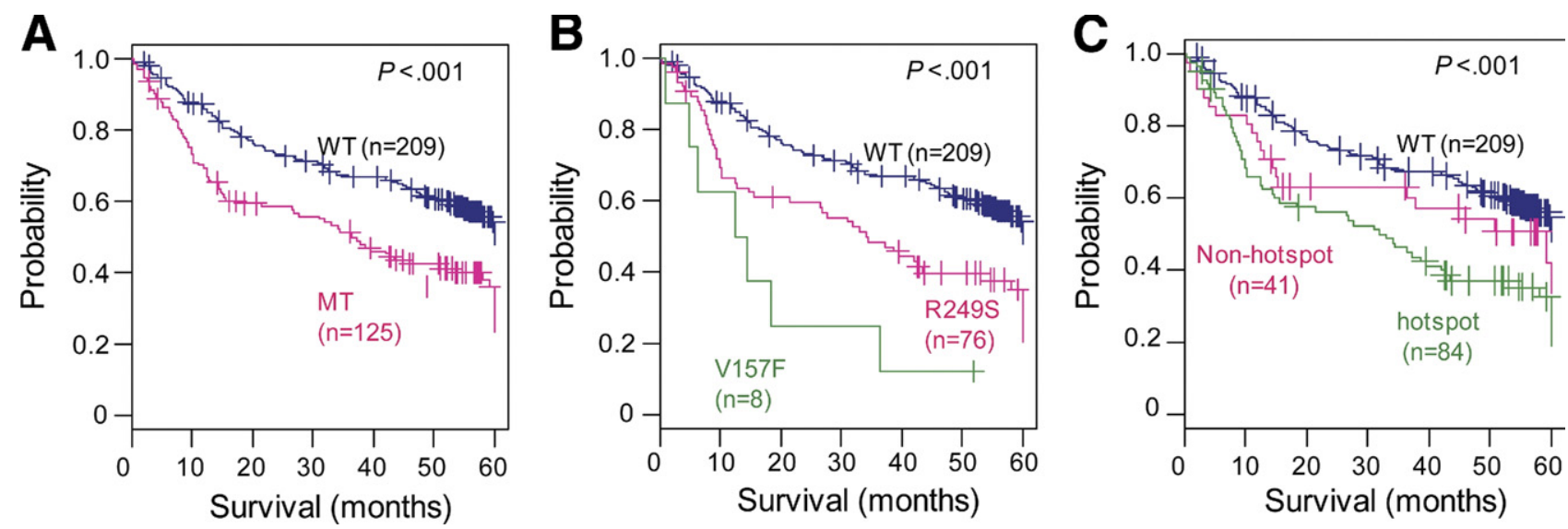

Figure 1. Prognostic values of TP53 mutation sites. (A) Kaplan-Meier plot for survival between the tumors of mutation-type (MT) and wild-type (WT) TP53. (B) Kaplan-Meier plot for survival between the tumors with R249S and V157F mutations. (C) Kaplan-Meier plot for survival between the tumors with hot spot (ie, R249S and V157F) and non-hot spot mutations. The + symbols in panels indicate censored data. 
Table 2. Multivariate Analysis for the Selected Clinical Features of HCC

\begin{tabular}{lcccr}
\hline & $\begin{array}{c}\text { Hazard } \\
\text { ratio }\end{array}$ & $\begin{array}{c}95 \% \mathrm{Cl} \\
\text { lower }\end{array}$ & $\begin{array}{c}95 \% \mathrm{Cl} \\
\text { upper }\end{array}$ & $P$ value \\
\hline Mutation, any type & & & & \\
Sex (male/female) & 1.09 & 0.67 & 1.79 & .730 \\
Age $(<50 / \geq 50, y)$ & 0.91 & 0.65 & 1.27 & .580 \\
AFP $(\geq 300 /<300 \mathrm{ng} / \mathrm{mL})$ & 1.76 & 1.24 & 2.50 & .002 \\
Size $(\geq 5 /<5 \mathrm{~cm})$ & 1.68 & 1.19 & 2.38 & .004 \\
Presence of cirrhosis & 0.99 & 0.68 & 1.43 & .950 \\
$\quad($ yes $/$ no) & & & & \\
Grade $($ III, IV/I, II) & 1.73 & 1.21 & 2.48 & .003 \\
TP53 mutation, any type & 1.79 & 1.29 & 2.51 & $<.001$ \\
Mutation category & & & & \\
Sex (male/female) & 1.07 & 0.65 & 1.75 & .800 \\
Age $(<50 / \geq 50, y)$ & 0.89 & 0.64 & 1.25 & .510 \\
AFP ( $\geq 300 /<300$ ng $/ \mathrm{mL})$ & 1.77 & 1.24 & 2.52 & .002 \\
Size $(\geq 5 /<5$ cm) & 1.71 & 1.21 & 2.43 & .003 \\
Presence of cirrhosis & 1.03 & 0.71 & 1.50 & .880 \\
$\quad$ (yes $/$ no) & & & & \\
$\quad$ Grade (III, IV/I, II) & 1.70 & 1.19 & 2.44 & .004 \\
Hot spot mutations & 1.97 & 1.36 & 2.86 & $<.001$ \\
$\quad$ Non-hot spot mutations & 1.47 & 0.88 & 2.44 & .140 \\
\hline
\end{tabular}

including TP53 mutations also revealed that only the hot spot mutations are independent risk factors for overall survival (HR, 1.79; 95\% CI: 1.29-2.51; $P<.001$, Table 2 ). These results suggest that the hot spot mutations mainly contribute to the heterogeneous progression of HCC.

Previously, classification of TP53 mutations based on the structural properties revealed distinct prognostic values in diffuse large B-cell lymphoma and squamous cell carcinoma of the head and neck. ${ }^{10,11}$ We therefore evaluated whether the structural classifications of TP53 mutations have different prognostic values in HCC. The TP53 mutations were categorized based on the structural properties as described in the TP53 mutation database of International Agency for Research on Cancer (Geneva, Switzerland; http://wwwp53.iarc.fr). The HCC patients with mutations at the DNA binding motifs (loop-L3) and S4 $\beta$-sandwich regions showed a significantly shorter survival compared with the wild-type TP53 patients (Supplementary Table 3). These results seem to be largely due to the profound prognostic values of the 2 hot spot mutations at codons 249 and 157, which are located in L3 and S4, respectively. However, mutations located outside the L3 or S4 were also associated with a poor prognosis albeit with a marginal significance $(P=.053$ and $P=.048$, respectively), indicating that these structural properties may not be proficient in classifying the prognostic outcome. We also applied another classification of disruptive vs nondisruptive mutations based on the mutation location and the predicted amino acid alterations. ${ }^{11}$ Differing from the previous analysis, both disruptive and nondisruptive mutations were associated with a worse prognosis $(P<.001$ and $P=.048$, respectively, Supplementary Table 3), which might be due to the nondisruptive nature of V157F mutation. These findings suggest that the hot spot mutation frequency rather than structural or functional classifications of TP53 mutations is a more significant prognostic indicator at least in the Chinese cohort.

The association of TP53 mutations with clinical features was also investigated (Supplementary Table 4). TP53 mutations were more frequent in the patients with high serum AFP level $(>300 \mathrm{ng} / \mathrm{mL})$ and patients without cirrhosis $(P<.05)$. Hotspot mutations were more frequent in young patients $(P=.019)$ and patients without cirrhosis $(P=.007)$. The association of TP53 mutation with HBV infection has been reported previously ${ }^{6,21}$; however, we could not assess this finding because most of the patients in our cohort were HBV infected.

Next, we tested whether a combination of clinicopathologic features and TP53 mutations could improve the stratification of the prognostic subgroups. Patients with TP53 mutations could be stratified according to a poor survival in each of the subpopulations with a low tumor grade (I, II), low serum AFP level $(<300 \mathrm{ng} / \mathrm{mL})$, large tumor size $(>5 \mathrm{~cm})$, or presence of cirrhosis (Figure 2 ). The patients with hot spot TP53 mutations showed similar prognostic values in these subpopulations (Supplementary Figure 1). These results suggest that a combined application of TP53 mutation status with the conventional clinical features would be a practical approach to predict the patient's survival.
A

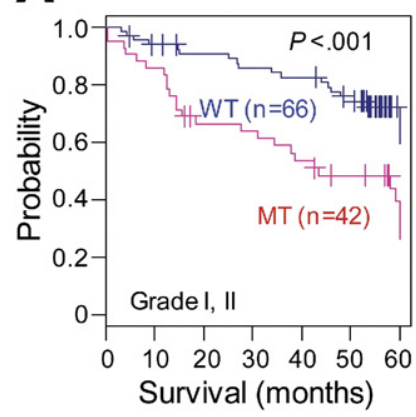

C

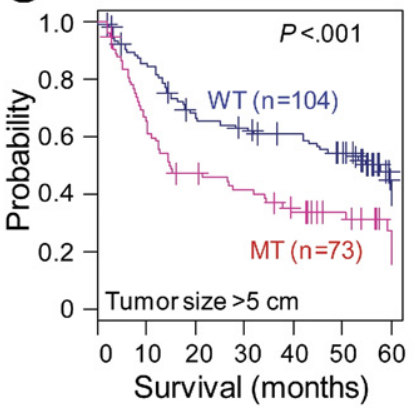

B

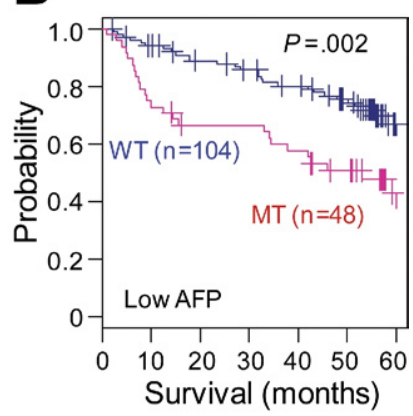

D

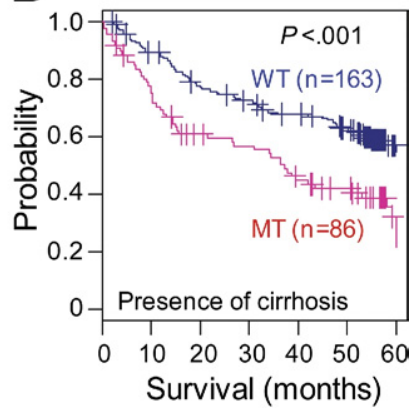

Figure 2. Prognostic value of combined status of TP53 mutation and other clinical features. $(A-D)$ Kaplan-Meier plots for survival between patients with mutation-type (MT) and wild-type (WT) TP53 in subpopulations of patients who have a low tumor grade (I, II) (A), low serum AFP level $(<300 \mathrm{ng} / \mathrm{mL})(B)$, large tumor size $(>5 \mathrm{~cm})(C)$, or cirrhosis $(D)$. The + symbols in panels indicate censored data. 
Gene Expression Profiles Reflect the Prognostic Value of TP53 Mutation Sites

Gene expression profile analysis was performed to characterize further the tumors according to the TP53 mutation status. A total of 366 HCC gene expression profiles having TP53 mutation status were compiled (see Materials and Methods section). It includes 238 Chinese samples with 89 cases of TP53 mutation and 128 white samples with 19 cases of TP53 mutation. We performed an unbiased estimation of the functional gene set enrichments using Gene Ontology (http://www.geneontology. org/) hierarchy. Considering the complexity of the TP53 biology and molecular heterogeneity of each sample, gene set enrichment analyses were performed on the individual HCC samples not the groups (see Materials and Methods section for details). The unbiased screening of the gene set enrichment revealed a profound increase in proliferation-related gene expression activity in the TP53 mutated tumors with the enrichment of transcription/ cell cycle-related functions (Supplementary Figure 2A). By contrast, the wild-type tumors were enriched with the metabolism-related genes, which may indicate a conservation of liver functions. The same patterns were observed in both Chinese $(n=238)$ and white $(n=128)$ cohorts. The comparison of hot spot and non-hot spot mutations was performed using the Chinese cohort because of the marked difference in the mutation frequency in the white cohort. Consistent with the different prognostic values, the proliferation-related genes were prevalently enriched in the hot spot-mutated tumors compared with the non-hot spot mutated tumors (Supplementary Figure $2 B$ ). These data indicate that the distinct prognostic significance of TP53 mutations, particularly the hot spot mutations, is a consequence of the molecular alterations rather than by-chance casual association with the clinical data.

\section{TP53 Mutations Are Associated With Stem Cell-Like Gene Expression Traits}

It has been suggested that the tumors originated from the stem/progenitor cells acquire a more aggressive phenotype in numerous cancer types. ${ }^{17,22}$ Moreover, several recent studies have shown association between TP53 mutations and the "stemness" of cancer cells (see also Discussion section). To address this issue in human tumor specimens, we measured the expression of stemness genes by the enrichment scores of multiple stem cellrelated genes rather than the expression of individual stem cell marker genes as described in previous study. ${ }^{17} \mathrm{It}$ has been suggested that detection of the activity of such stemness-related complex networks rather than the expression of individual genes is more important because different ES regulators may activate stem-cell regulatory networks in each tumors. Enrichment of various ES and HB-related gene signatures (for details see Materials and Methods section) was calculated in individual tumors of the HCC data set $(\mathrm{n}=366)$. We found that the ES-related and $\mathrm{HB}$ signatures were concomitantly enriched in the TP53 mutated tumors but repressed in the wild-type tumors (Figure $3 A$ ). To exclude the contribution of the proliferation-related genes in the stem cell signature, we tested the enrichment of the signatures after subtracting the proliferation-related genes as described previously. ${ }^{17}$ The results were similar suggesting that the enrichment of the stem cell-related signatures in the TP53 mutated tumors was independent of the expression of proliferation-related genes (Figure $3 A$, right). In addition, when the tumors were classified according to the status of stem cell-like expression (ie, HB and ES) and hot spot TP53 mutation, they showed correlation with patient's survival, supporting the prognostic significance of TP53 mutation and stem cell traits (Figure $3 B$ ). Classification with mutations with any types (MT vs WT) also demonstrated a similar result (Supplementary Figure 3).

The generality of our finding was evaluated by extending our analysis to the public data sets of breast cancer $(\mathrm{n}=251)$ and lung cancer $(\mathrm{n}=218)$ using the Gene Set Enrichment Analysis method. ${ }^{19}$ Similar to HCC, there was a significant up-regulation of ES trait in the TP53 mutated tumors compared with wild-type breast and lung cancers (Figure $3 B$ and $C$ and Supplementary Table 5). These findings suggest that the stem cell-like traits are a common feature of tumors harboring TP53 mutations.

\section{Validation of Stem Cell-Like Gene Expression in TP53 Mutated Tumors}

Next, we evaluated the expression of stemnessrelated genes and identified 14 differentially overexpressed genes in mutated tumors compared with wildtype tumors by performing 10,000 permuted 2-sample $t$ test $(P<.01)$ with greater than 2 -fold difference (Supplementary Table 6). Notably, CD24 highly expressed in TP53 mutated as compared with wild-type tumors. CD24 has been proposed as a stemness marker in numerous types of cancers including ovary, ${ }^{23}$ pancreas, ${ }^{24}$ and colon cancers. ${ }^{25}$ In addition, AFP was found in the gene list, which is recognized as a cancer stem cell marker in combination with epithelial cell adhesion molecule in HCC. ${ }^{26}$ To confirm our finding, the expression levels of $C D 24$ and AFP were measured by real-time quantitative PCR on 75 samples of mutant type (MT, $\mathrm{n}=31$ ) and wild-type (WT, $\mathrm{n}=44$ ) HCC. Significant overexpression of CD24 and AFP was found in the mutant as compared with the wild-type tumors (Mann-Whitney $U$ test, $P<$ .0001 , Figure $4 A$ and $B$ ). Taken together, our results support the association of TP53 mutations with the enriched expression of stemness-related traits.

\section{Discussion}

In this study, we demonstrate that the TP53 mutations in Chinese HCC are associated with poor clinical 
A

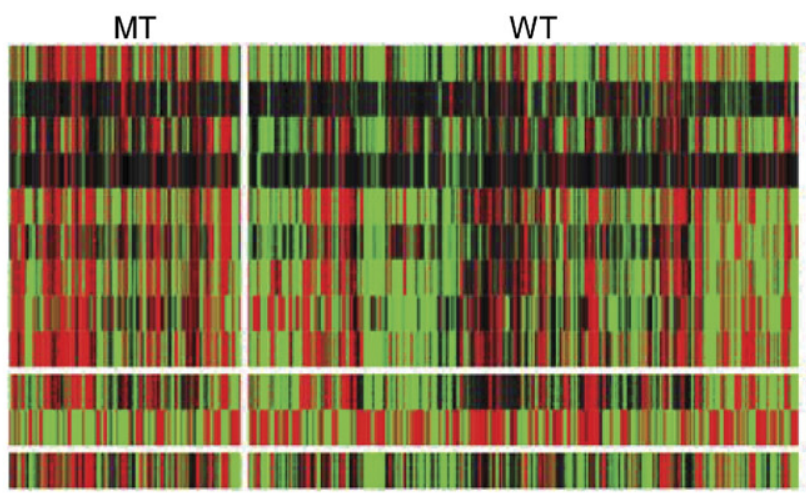

mָiornm Enrichment scores

B

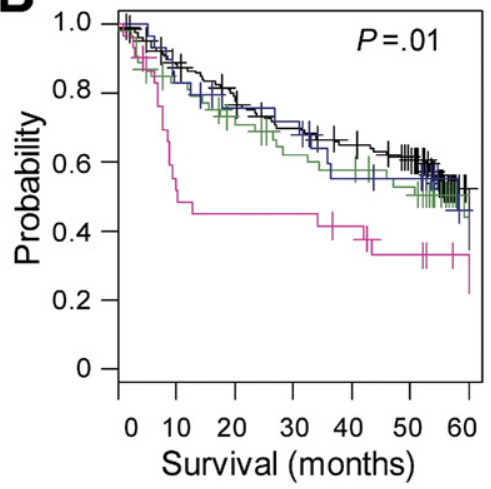

ES-WT ( $n=193)$

ES-hotspot $(n=33)$

$E S+W T(n=65)$

ES+hotspot $(n=33)$

C
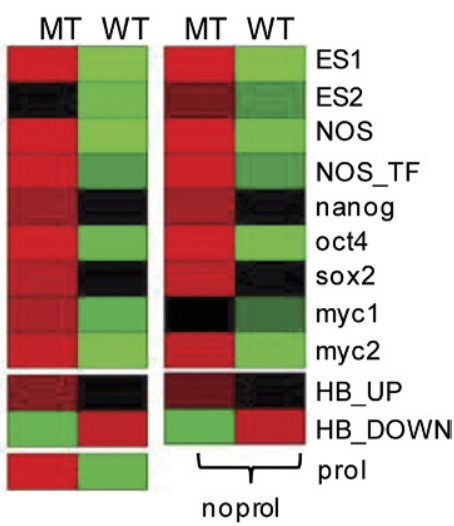

noprol

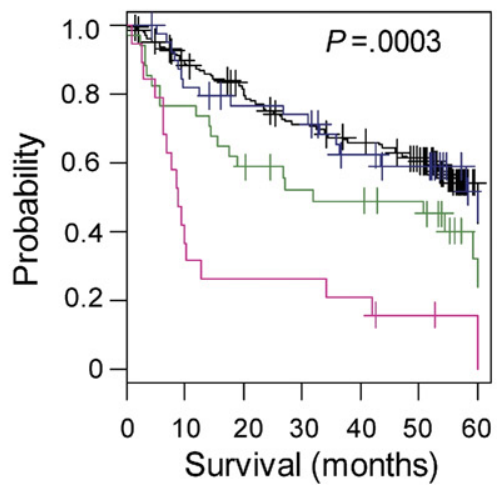

HB-WT $(n=215)$

HB-hotspot $(n=47)$

$H B+W T(n=43)$

HB+hotspot $(n=190)$

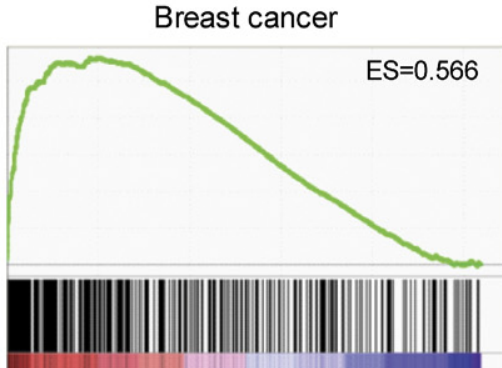

Lung cancer

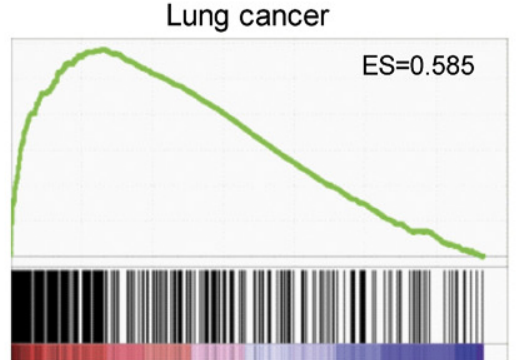

Figure 3. Expression of stem cell-like traits in TP53 mutated tumors. (A) The enrichment scores for the ES signatures and HB signatures in the compiled HCC data set are shown on the left; the enrichment in groups of mutation type (MT) and wild type (WT) is shown in the middle; and the enrichments of ES signature without the proliferation-related genes (noprol) are shown on the right. The enrichment scores in each sample and group represent $-\log _{10}$ ( $P$ value) calculated by hypergeometric test. (B) Based on the expression status of ES1 (upper) or HB (lower) signatures and the hot spot TP53 mutation status, the 366 patients were stratified into 4 groups. Forty-two cases of non-hot spot mutations were not included in the analysis. ES + represent the tumors that were enriched with ES1 signature $(P<.01)$, whereas other tumors were indicated as ES - . HB + represents the tumors that were positively enriched with HB_UP and negatively enriched with HB_DOWN signatures $(P<.01)$, whereas other tumors were indicated as HB-. (C) The plots showed the enrichment scores (ES) for the ES1 signature in breast cancers (upper), and lung cancers (lower) were calculated by Gene Set Enrichment Analysis method.

outcome. In particular, the hot spot mutations, ie, R249S and V157F, are strongly associated with bad prognosis. Evaluation of site-specific prognostic values of mutations may be helpful in delineating mutant p53 functions as well as their clinical implication.

The reason(s) for the worse prognostic feature associated with the hot spot mutations of TP53 is unclear. It has been suggested that the hot spot mutations, arising from the clonal expansion of the mutated cells during cancer progression, can provide a selective advantage for tumor cell survival ${ }^{27}$ and/or that they are more deleterious than the non-hot spot mutations. ${ }^{28}$ Indeed, accumulating evidence supports the functional alterations of the hot spot mutations, ie, R249S and V157F. ${ }^{29-31}$ It is also 

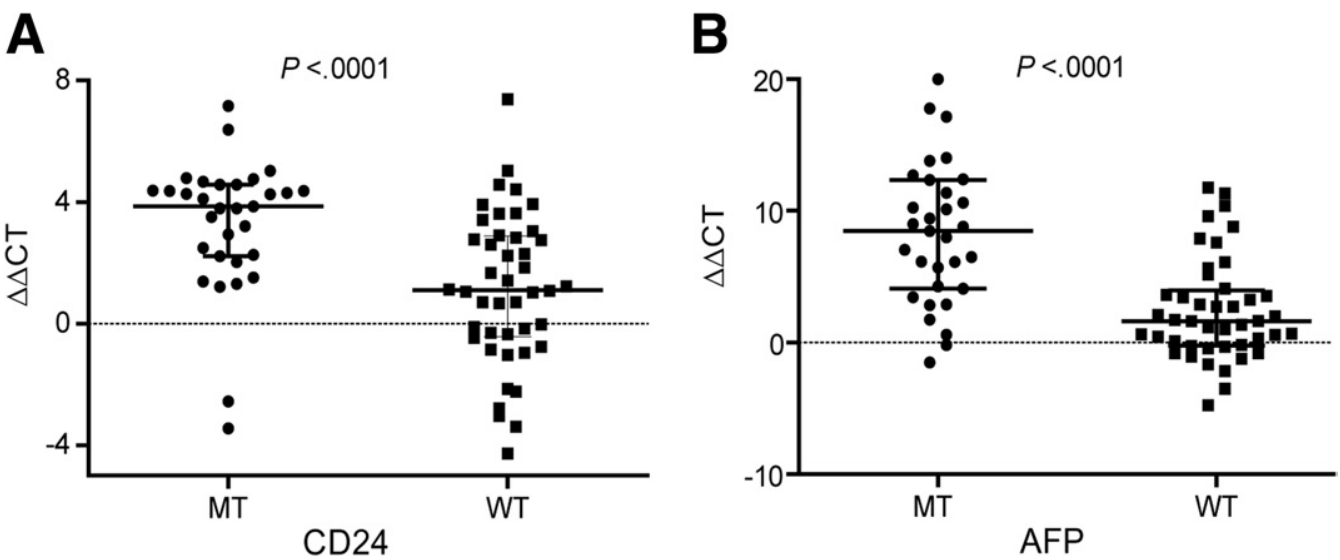

Figure 4. Validation of $C D 24$ and $A F P$ expression by quantitative polymerase chain reaction. $(A$ and $B)$ Expression of $C D 24(A)$ and $A F P(B)$ levels in mutant type (MT, $n=31$ ) and wild-type $(W T, n=44)$ HCCs were measured by quantitative polymerase chain reaction. Statistical significance was tested by 2-tailed Mann-Whitney $U$ test. Median and interquartile ranges were indicated by horizontal lines.

possible that the different mode of actions can contribute to their prognostic distinction. R249S is frequently found, both in normal and in cirrhotic liver, in high aflatoxin B1 exposure area, suggesting that R249S mutation occurs at the early stage of hepatocarcinogenesis, whereas other mutations seem to be more prevalent at later stages. ${ }^{32,33}$ Similarly, in lung cancer, V157F is frequently found in close association with cigarette smoking. ${ }^{27}$ These hot spot-specific features caused by the environmental exposure of mutagens result in $G$ to $T$ transversion and may be involved in the development of more aggressive phenotypes. However, considering the complexity of p53 biology, further studies are needed to delineate the mechanisms by which the hot spot mutations result in a worse prognosis.

We arbitrarily classified the tumors into hot spot vs non-hot spot mutated tumors with mutation frequency of $2 \%$. However, the prognostic values of the hot spot TP53 mutations are well reflected in their corresponding gene expression profiles. These data support the notion that the worse prognostic value of the hot spot mutations is not likely to be a biased observation because of the large number of cases or arbitrary classification. In addition, we found that the TP53 mutations are accompanied by the expression of stem cell-like traits. Although further validation was not performed here for the causal link between TP53 mutations and stem cell traits, it was already known that the p53 is involved in the stem cells' self-renewal by suppressing NANOG expression. ${ }^{34}$ It has also been shown that neural stem cells harboring TP53 mutations have increased potential to accumulate genetic lesions and generate glioblastomatosis. ${ }^{35}$ Moreover, it was recently shown that TP53 is critical for reprogramming of differentiated cells into pluripotent stem cells. ${ }^{36}$ Similarly, our data support the view that the acquisition of stem cell-like traits in the TP53 mutated tumors play an important role in the generation and/or progression of poor prognostic phenotype. Accordingly, the invalida- tion of stem-stem traits might be a novel potential therapeutic strategy especially for the TP53 mutated tumors.

In the present study, we observed the differential expression of the well-known putative cancer stem cell markers, ie, CD24 and AFP in TP53 mutated tumors compared with wild-type tumors; however, other putative liver cancer stem cell markers were not differentially expressed. ${ }^{37-39}$ This might be due to the population heterogeneity of the stem-like tumors as well as TP53 mutated tumors activating different ES cell regulators. However, our data collectively suggest that the acquisition of stem-like trait in TP53 mutated tumors is a likely explanation for the aggressive phenotype of TP53 mutated tumors.

In conclusion, we demonstrate that the TP53 mutations, particularly hot spot mutations, represent an independent risk factor for a shorter survival of the HCC patients. The acquisition of stem cell-like phenotype likely contributes to the aggressive behavior of TP53 mutated tumors. Our results may therefore have prognostic and therapeutic implications for the future management of HCC patients with TP53 mutations.

\section{Supplementary Material}

Note: To access the supplementary material accompanying this article, visit the online version of Gastroenterology at www.gastrojournal.org, and at doi: $10.1053 /$ j.gastro.2010.11.034.

\section{References}

1. Parkin DM, Bray F, Ferlay J, et al. Global cancer statistics, 2002. CA Cancer J Clin 2005;55:74-108.

2. El-Serag HB. Hepatocellular carcinoma: recent trends in the United States. Gastroenterology 2004;127:S27-S34.

3. Hayashi $\mathrm{H}$, Sugio K, Matsumata $\mathrm{T}$, et al. The clinical significance of p53 gene mutation in hepatocellular carcinomas from Japan. Hepatology 1995;22:1702-1707. 
4. Honda K, Sbisa E, Tullo A, et al. p53 Mutation is a poor prognostic indicator for survival in patients with hepatocellular carcinoma undergoing surgical tumour ablation. Br J Cancer 1998;77:776-782.

5. Yano M, Hamatani K, Eguchi $\mathrm{H}$, et al. Prognosis in patients with hepatocellular carcinoma correlates to mutations of p53 and/or hMSH2 genes. Eur J Cancer 2007;43:1092-1100.

6. Hussain SP, Schwank J, Staib F, et al. TP53 mutations and hepatocellular carcinoma: insights into the etiology and pathogenesis of liver cancer. Oncogene 2007;26:2166-2176.

7. Soussi T, Wiman K. Shaping genetic alterations in human cancer: the p53 mutation paradigm. Cancer Cell 2007;12:303-312.

8. Hsu IC, Metcalf RA, Sun T, et al. Mutational hotspot in the p53 gene in human hepatocellular carcinomas. Nature 1991;350:427-428.

9. Ozturk M. p53 Mutation in hepatocellular carcinoma after aflatoxin exposure. Lancet 1991;338:1356-1359.

10. Young KH, Leroy K, Moller MB, et al. Structural profiles of TP53 gene mutations predict clinical outcome in diffuse large B-cell lymphoma: an international collaborative study. Blood 2008; 112:3088-3098.

11. Poeta ML, Manola J, Goldwasser MA, et al. TP53 mutations and survival in squamous-cell carcinoma of the head and neck. N Engl J Med 2007;357:2552-2561.

12. Brosh R, Rotter V. When mutants gain new powers: news from the mutant p53 field. Nat Rev Cancer 2009;9:701-713.

13. Jia HL, Ye QH, Qin LX, et al. Gene expression profiling reveals potential biomarkers of human hepatocellular carcinoma. Clin Cancer Res 2007;13:1133-1139.

14. Boyault S, Rickman DS, de Reynies A, et al. Transcriptome classification of HCC is related to gene alterations and to new therapeutic targets. Hepatology 2007;45:42-52.

15. Miller LD, Smeds J, George J, et al. An expression signature for p53 status in human breast cancer predicts mutation status, transcriptional effects, and patient survival. Proc Natl Acad Sci U S A 2005;102:13550-13555.

16. Takeuchi T, Tomida S, Yatabe Y, et al. Expression profile-defined classification of lung adenocarcinoma shows close relationship with underlying major genetic changes and clinicopathologic behaviors. J Clin Oncol 2006;24:1679-1688.

17. Ben-Porath I, Thomson MW, Carey VJ, et al. An embryonic stem cell-like gene expression signature in poorly differentiated aggressive human tumors. Nat Genet 2008;40:499-507.

18. Petkov PM, Zavadil J, Goetz D, et al. Gene expression pattern in hepatic stem/progenitor cells during rat fetal development using complementary DNA microarrays. Hepatology 2004;39:617-627.

19. Subramanian A, Tamayo P, Mootha VK, et al. Gene set enrichment analysis: a knowledge-based approach for interpreting genome-wide expression profiles. Proc Natl Acad Sci U S A 2005; 102:15545-15550.

20. Oda T, Tsuda H, Scarpa A, et al. p53 Gene mutation spectrum in hepatocellular carcinoma. Cancer Res 1992;52:6358-6364.

21. Kirk GD, Lesi OA, Mendy M, et al. 249(ser) TP53 mutation in plasma DNA, hepatitis $B$ viral infection, and risk of hepatocellular carcinoma. Oncogene 2005;24:5858-5867.

22. Lee JS, Heo J, Libbrecht L, et al. A novel prognostic subtype of human hepatocellular carcinoma derived from hepatic progenitor cells. Nat Med 2006;12:410-416.

23. Gao MQ, Choi YP, Kang S, et al. CD24+ cells from hierarchically organized ovarian cancer are enriched in cancer stem cells. Oncogene 2010;29:2672-2680.

24. Li C, Heidt DG, Dalerba P, et al. Identification of pancreatic cancer stem cells. Cancer Res 2007;67:1030-1037.

25. Yeung TM, Gandhi SC, Wilding JL, et al. Cancer stem cells from colorectal cancer-derived cell lines. Proc Natl Acad Sci U S A 2010;107:3722-3727.
26. Yamashita T, Forgues M, Wang W, et al. EpCAM and $\alpha$-fetoprotein expression defines novel prognostic subtypes of hepatocellular carcinoma. Cancer Res 2008;68:1451-1461.

27. Sidransky D, Mikkelsen T, Schwechheimer K, et al. Clonal expansion of p53 mutant cells is associated with brain tumour progression. Nature 1992;355:846-847.

28. Petitjean A, Mathe $\mathrm{E}$, Kato $\mathrm{S}$, et al. Impact of mutant p53 functional properties on TP53 mutation patterns and tumor phenotype: lessons from recent developments in the IARC TP53 database. Hum Mutat 2007;28:622-629.

29. Mizuarai S, Yamanaka K, Kotani H. Mutant p53 induces the GEF-H1 oncogene, a guanine nucleotide exchange factor-H1 for RhoA, resulting in accelerated cell proliferation in tumor cells. Cancer Res 2006;66:6319-6326.

30. Dumenco L, Oguey D, Wu J, et al. Introduction of a murine p53 mutation corresponding to human codon 249 into a murine hepatocyte cell line results in growth advantage, but not in transformation. Hepatology 1995;22:1279-1288.

31. Ghebranious N, Sell S. The mouse equivalent of the human p53ser249 mutation p53ser246 enhances aflatoxin hepatocarcinogenesis in hepatitis B surface antigen transgenic and p53 heterozygous null mice. Hepatology 1998;27:967-973.

32. Aguilar F, Harris CC, Sun T, et al. Geographic variation of p53 mutational profile in nonmalignant human liver. Science 1994; 264:1317-1319.

33. Teramoto T, Satonaka K, Kitazawa S, et al. p53 Gene abnormalities are closely related to hepatoviral infections and occur at a late stage of hepatocarcinogenesis. Cancer Res 1994;54:231235.

34. Lin T, Chao C, Saito S, et al. p53 Induces differentiation of mouse embryonic stem cells by suppressing Nanog expression. Nat Cell Biol 2005;7:165-171.

35. Wang $\mathrm{Y}$, Yang J, Zheng $\mathrm{H}$, et al. Expression of mutant $\mathrm{p} 53$ proteins implicates a lineage relationship between neural stem cells and malignant astrocytic glioma in a murine model. Cancer Cell 2009;15:514-526.

36. Hong $\mathrm{H}$, Takahashi $\mathrm{K}$, Ichisaka $\mathrm{T}$, et al. Suppression of induced pluripotent stem cell generation by the p53-p21 pathway. Nature 2009;460:1132-1135.

37. Ma S, Chan KW, Hu L, et al. Identification and characterization of tumorigenic liver cancer stem/progenitor cells. Gastroenterology 2007;132:2542-2556.

38. Yang ZF, Ho DW, Ng MN, et al. Significance of CD90+ cancer stem cells in human liver cancer. Cancer Cell 2008;13:153-166.

39. Klonisch T, Wiechec E, Hombach-Klonisch S, et al. Cancer stem cell markers in common cancers: therapeutic implications. Trends Mol Med 2008;14:450-460.

Received January 19, 2010. Accepted November 10, 2010.

\section{Reprint requests}

Address requests for reprints to: Snorri S. Thorgeirsson, MD, Laboratory of Experimental Carcinogenesis, Center for Cancer Research, National Cancer Institute, National Institutes of Health, 37 Convent Drive MSC 4262, Building 37, Room 4146A, Bethesda, Maryland 20892. e-mail: snorri_thorgeirsson@nih.gov.

\section{Conflicts of interest}

The authors disclose no conflicts.

\section{Funding}

Supported by the Intramural Research Program of the NIH, National Cancer Institute, Center for Cancer Research, and a research grant of the Ajou University School of Medicine, Suwon, Korea (3-2010027-0, 2010). 
Supplementary Table 1. List of Primer Sequences for TP53 Mutation Analysis

\begin{tabular}{|c|c|c|}
\hline Exons & Name & Sequence \\
\hline \multicolumn{3}{|c|}{ Primers for genomic DNA } \\
\hline \multirow[t]{2}{*}{ Exon5 } & p53_5_s & 5'-TCCTACAGTACTCCCCTGCC-3' \\
\hline & p53_5_AS & 5'-GCCCCAGCTGCTCACCATC-3' \\
\hline \multirow[t]{2}{*}{ Exon6 } & p53_6_s & 5'-ACTGATTGCTCTTAGGTCTG-3' \\
\hline & p53_6_AS & 5'-AGTTGCAAACCAGACCTCAG-3' \\
\hline \multirow[t]{2}{*}{ Exon7 } & p53_7_s & 5'-AGGTTGGCTCTGACTGTACC-3' \\
\hline & p53_7_AS & 5'-CTCCTGACCTGGAGTCTTCC-3' \\
\hline \multirow[t]{2}{*}{ Exon8 } & p53_8_s & 5'-CTATCCTGAGTAGTGGTAATC-3' \\
\hline & p53_8_AS & 5'-GTCCTGCTTGCTTACCTCGC-3' \\
\hline \multicolumn{3}{|c|}{ Primers for cDNA } \\
\hline \multirow[t]{2}{*}{ Exon5 } & p53_5_s & 5'-GTCTGGGCTTCTTGCATTCT-3' \\
\hline & p53_5_AS & 5'-ACACGCAAATTTCCTTCCAC-3' \\
\hline \multirow[t]{2}{*}{ Exon6 } & p53_6_s & 5'-CATGAGCGCTGCTCAGATAG-3' \\
\hline & p53_6_AS & 5'-GCCCATGCAGGAACTGTTA-3' \\
\hline \multirow[t]{2}{*}{ Exon7 } & p53_7_s & 5'-AGGTTGGCTCTGACTGTACC-3' \\
\hline & p53_7_AS & 5'-СTCCTGACCTGGAGTCTTCC-3' \\
\hline \multirow[t]{2}{*}{ Exon8 } & p53_8_s & 5'-CСTCACCATCATCACACTGG-3' \\
\hline & p53_8_AS & 5'-CTTCTTTGGCTGGGGAGAG-3' \\
\hline
\end{tabular}


Supplementary Table 2. List of TP53 Mutations in Chinese and White HCC Cohorts

\begin{tabular}{|c|c|c|c|c|c|c|}
\hline No. & ID & Geographic region & Mutation & Wild type & Mutation type & Double mutation \\
\hline 1 & $\mathrm{HCCOO8}$ & Belgium & R249S & AGG & AGT & R213R \\
\hline 2 & HCC012 & Belgium & R249S & $A G G$ & AGC & \\
\hline 3 & НСС030 & Qidong & R249S & $A G G$ & AGT & \\
\hline 4 & HCC031 & Qidong & R249S & $A G G$ & AGT & \\
\hline 5 & $\mathrm{HCCO} 32$ & Qidong & R249S & AGG & AGT & \\
\hline 6 & $\mathrm{HCCO} 33$ & Qidong & R249S & AGG & AGT & \\
\hline 7 & HCC035 & Qidong & Y220C & TAT & TGT & \\
\hline 8 & HCC039 & Qidong & R249S & $A G G$ & AGT & \\
\hline 9 & $\mathrm{HCCO} 40$ & Qidong & R249S & AGG & AGC & \\
\hline 10 & HCC041 & Qidong & R249S & AGG & AGT & \\
\hline 11 & $\mathrm{HCC} 043$ & Qidong & G245C & GGC & GTC & \\
\hline 12 & $\mathrm{HCCO} 44$ & Qidong & R249S & $A G G$ & AGT & \\
\hline 13 & $\mathrm{HCCO} 45$ & Qidong & R249S & AGG & AGT & \\
\hline 14 & $\mathrm{HCCO} 47$ & Qidong & G245V & GGC & GGT & \\
\hline 15 & HCC051 & Qidong & D184Y & GAT & TAT & \\
\hline 16 & HCC054 & Qidong & V157F & GTC & TTC & \\
\hline 17 & HCC055 & Qidong & R249S & AGG & AGT & \\
\hline 18 & HCC056 & Qidong & $294 \mathrm{del} / \mathrm{fs}$ & & & \\
\hline 19 & HCC062 & Qidong & R249S & AGG & AGT & \\
\hline 20 & HCC063 & Qidong & R273L & CGT & CTT & \\
\hline 21 & HCC064 & Qidong & R249S & AGG & AGT & \\
\hline 22 & HCC066 & Qidong & E298X & GAG & TAG & \\
\hline 23 & $\mathrm{HCC067}$ & Qidong & R249S & AGG & AGT & \\
\hline 24 & HCC068 & Qidong & R249S & AGG & AGT & \\
\hline 25 & HCC069 & Qidong & V157F & GTC & TTC & \\
\hline 26 & HCCO70 & Qidong & $\mathrm{R} 213 \mathrm{X}$ & CGA & TGA & \\
\hline 27 & HCC071 & Qidong & R249S & AGG & AGT & \\
\hline 28 & HCCO73 & Qidong & V157F & GTC & TTC & \\
\hline 29 & $\mathrm{HCCO} 74$ & Qidong & R249S & AGG & AGT & \\
\hline 30 & HCCO75 & Qidong & R249S & AGG & AGT & \\
\hline 31 & HCC076 & Qidong & R249S & AGG & AGT & \\
\hline 32 & HCC077 & Qidong & R249S & AGG & AGT & \\
\hline 33 & $\mathrm{HCCO} 78$ & Qidong & R249S & AGG & AGT & \\
\hline 34 & HCCO79 & Qidong & R249S & AGG & AGT & \\
\hline 35 & $\mathrm{HCC} 080$ & Qidong & R249S & AGG & AGT & \\
\hline 36 & HCC082 & Qidong & R249S & AGG & AGT & \\
\hline 37 & HCC084 & Qidong & R249S & AGG & AGT & \\
\hline 38 & HCC085 & Qidong & R249S & AGG & AGT & \\
\hline 39 & HCC088 & Qidong & A159P & GCC & $\mathrm{CCC}$ & \\
\hline 40 & HCC089 & Qidong & V157F & GTC & TTC & \\
\hline 41 & HCC090 & Qidong & A159P & GCC & $\mathrm{CcC}$ & \\
\hline 42 & HCC096 & Belgium & R213R & CGA & CGG & \\
\hline 43 & HCC107 & Belgium & R249S & AGG & AGT & \\
\hline 44 & HCC120 & United States & V157F & GTC & TTC & \\
\hline 45 & HCC122 & United States & R213R & CGA & CGG & \\
\hline 46 & HCC138 & United States & V157F & GTC & TTC & \\
\hline 47 & HCC142 & Qidong & R249S & AGG & AGT & \\
\hline 48 & HCC143 & Qidong & R249S & $A G G$ & AGT & \\
\hline 49 & HCC145 & Qidong & R248W & CGG & TGG & R249S \\
\hline 50 & HCC146 & Qidong & G245V & GGC & GTC & \\
\hline 51 & HCC147 & Qidong & R249M & AGG & ATG & \\
\hline 52 & HCC148 & Qidong & R249S & AGG & AGT & \\
\hline 53 & HCC149 & Qidong & R249S & AGG & AGT & \\
\hline 54 & HCC154 & Qidong & R249S & AGG & AGT & \\
\hline 55 & HCC157 & Qidong & R249S & AGG & AGT & \\
\hline 56 & HCC162 & Qidong & R249S & AGG & AGT & \\
\hline 57 & HCC164 & Qidong & V157F & GTC & TTC & \\
\hline 58 & HCC165 & Qidong & R249S & AGG & AGT & \\
\hline 59 & HCC167 & Qidong & V157F & GTC & TTC & \\
\hline 60 & HCC168 & Qidong & R249S & AGG & AGT & \\
\hline 61 & HCC169 & Qidong & R249S & AGG & AGT & \\
\hline 62 & $\mathrm{HCC} 170$ & Qidong & R249S & AGG & AGT & \\
\hline 63 & HCC171 & Qidong & R249S & AGG & AGT & \\
\hline
\end{tabular}


Supplementary Table 2. Continued

\begin{tabular}{|c|c|c|c|c|c|c|}
\hline No. & ID & Geographic region & Mutation & Wild type & Mutation type & Double mutation \\
\hline 64 & HCC175 & Qidong & R249S & $A G G$ & AGT & \\
\hline 65 & HCC176 & Qidong & R249S & $A G G$ & AGC & \\
\hline 66 & HCC181 & Qidong & $1255 \mathrm{~S}$ & ATC & AGC & \\
\hline 67 & HCC190 & Qidong & R249S & $A G G$ & AGT & \\
\hline 68 & HCC191 & Qidong & V157F & GTC & TTC & R249S \\
\hline 69 & HCC193 & Qidong & R249S & $A G G$ & AGT & \\
\hline 70 & HCC194 & Qidong & R249S & AGG & AGT & \\
\hline 71 & HCC196 & Qidong & R249S & $A G G$ & AGT & \\
\hline 72 & HCC199 & Qidong & R249S & $A G G$ & AGT & \\
\hline 73 & $02-285 A$ & Shanghai & R249S & $A G G$ & AGT & \\
\hline 74 & $02-314 A$ & Shanghai & H193R & CAT & CGT & \\
\hline 75 & $02-345 A$ & Shanghai & R249S & $A G G$ & AGC & \\
\hline 76 & $02-346 \mathrm{~A}$ & Shanghai & G199V & GGA & GTA & \\
\hline 77 & $02-354 \mathrm{~A}$ & Shanghai & G266R & GGA & AGA & \\
\hline 78 & $02-355 A$ & Shanghai & $\mathrm{I} 195 \mathrm{~F}$ & ATC & TTC & \\
\hline 79 & $02-361 \mathrm{~A}$ & Shanghai & R249S & AGG & AGT & \\
\hline 80 & $02-366 A$ & Shanghai & S127P & TCC & $\mathrm{CCC}$ & \\
\hline 81 & $02-407 A$ & Shanghai & H193R & CAT & CGT & \\
\hline 82 & $02-416 \mathrm{~A}$ & Shanghai & R249S & AGG & AGT & \\
\hline 83 & $02-423 \mathrm{~A}$ & Shanghai & R249S & AGG & AGT & \\
\hline 84 & $02-424 \mathrm{~A}$ & Shanghai & R249S & $A G G$ & AGT & \\
\hline 85 & $02-427 \mathrm{~A}$ & Shanghai & R249S & $A G G$ & AGT & \\
\hline 86 & $02-432 A$ & Shanghai & R249S & AGG & AGT & \\
\hline 87 & $02-454 \mathrm{~A}$ & Shanghai & C135Y & $\mathrm{TGC}$ & TAC & \\
\hline 88 & $02-458 \mathrm{~A}$ & Shanghai & R249S & AGG & AGT & \\
\hline 89 & $02-460 A$ & Shanghai & R249S & $A G G$ & AGT & \\
\hline 90 & $02-461 \mathrm{~A}$ & Shanghai & A159P & GCC & $\mathrm{CCC}$ & \\
\hline 91 & $02-466 \mathrm{~A}$ & Shanghai & R249S & $A G G$ & AGT & \\
\hline 92 & 03-017A & Shanghai & R174W & $A G G$ & TGG & \\
\hline 93 & 03-025A & Shanghai & R249S & $A G G$ & AGT & \\
\hline 94 & 03-047A & Shanghai & R267P & CGG & ССТ & N268D \\
\hline 95 & 03-057A & Shanghai & T253S & ACC & TCC & \\
\hline 96 & 03-058A & Shanghai & R249S & $A G G$ & AGT & \\
\hline 97 & 03-062A & Shanghai & R306X & CGA & TGA & \\
\hline 98 & 03-093A & Shanghai & R249S & AGG & AGT & \\
\hline 99 & 03-099A & Shanghai & R249S & AGG & AGT & \\
\hline 100 & $03-102 A$ & Shanghai & G244D & GGC & GAC & \\
\hline 101 & 03-147A & Shanghai & R249S & $A G G$ & AGT & \\
\hline 102 & 03-148A & Shanghai & S127P & TCC & $\mathrm{CCC}$ & \\
\hline 103 & 03-164A & Shanghai & R249S & AGG & AGT & \\
\hline 104 & 03-187A & Shanghai & N239N & & & \\
\hline 105 & 03-197A & Shanghai & R175L & CGC & СТC & \\
\hline 106 & 03-199A & Shanghai & C176S & TGC & TCC & \\
\hline 107 & $03-210 A$ & Shanghai & R249S & $A G G$ & AGT & \\
\hline 108 & $03-211 \mathrm{~A}$ & Shanghai & G266V & GGA & GTA & \\
\hline 109 & 03-213A & Shanghai & Y236C & TAC & TGC & \\
\hline 110 & 03-219A & Shanghai & R280G & AGA & GGA & \\
\hline 111 & 03-228A & Shanghai & I232T & ATC & ACC & \\
\hline 112 & $03-231 \mathrm{~A}$ & Shanghai & $\mathrm{K} 132 \mathrm{~N}$ & AAG & AAT & \\
\hline 113 & 03-233А & Shanghai & R249S & AGG & AGT & \\
\hline 114 & $03-235 A$ & Shanghai & R249S & AGG & AGC & \\
\hline 115 & $03-248 A$ & Shanghai & C182X & TGC & TGA & \\
\hline 116 & 03-268A & Shanghai & V157F & GTC & TTC & \\
\hline 117 & 03-273A & Shanghai & R249S & $A G G$ & AGT & \\
\hline 118 & 03-277A & Shanghai & R249S & AGG & AGT & \\
\hline 119 & $03-278 A$ & Shanghai & $\mathrm{I} 162 \mathrm{~F}$ & ATC & TTC & \\
\hline 120 & 03-280A & Shanghai & R249S & $A G G$ & AGT & \\
\hline 121 & $03-305 A$ & Shanghai & R249S & AGG & AGT & \\
\hline 122 & 03-313A & Shanghai & R249S & AGG & AGT & \\
\hline 123 & 03-314A & Shanghai & $\mathrm{C} 277 \mathrm{~F}$ & TGT & $\mathrm{TTT}$ & \\
\hline 124 & 03-316A & Shanghai & R249S & AGG & AGT & \\
\hline 125 & 03-326A & Shanghai & R249S & AGG & AGT & \\
\hline 126 & 03-333А & Shanghai & R249S & AGG & AGT & \\
\hline
\end{tabular}


Supplementary Table 2. Continued

\begin{tabular}{|c|c|c|c|c|c|c|}
\hline No. & ID & Geographic region & Mutation & Wild type & Mutation type & Double mutation \\
\hline 127 & 03-335A & Shanghai & R249S & AGG & AGT & \\
\hline 128 & 03-359A & Shanghai & R249S & AGG & AGT & \\
\hline 129 & 03-366A & Shanghai & G245S & GGC & AGC & \\
\hline 130 & $03-381 \mathrm{~A}$ & Shanghai & A159P & GCC & $\mathrm{CCC}$ & \\
\hline 131 & 03-387A & Shanghai & V272M & GTG & ATG & \\
\hline 132 & $03-425 A$ & Shanghai & R249S & AGG & AGT & \\
\hline 133 & $03-450 A$ & Shanghai & K164X & AAG & TAG & \\
\hline 134 & $03-468 \mathrm{~A}$ & Shanghai & del126-133 & & & \\
\hline
\end{tabular}

Supplementary Table 3. Univariate Test for the Structural

Classification of TP53 Mutations in

Chinese Cohort

\begin{tabular}{lccccr}
\hline $\begin{array}{c}\text { Structural } \\
\text { classification }\end{array}$ & $\begin{array}{c}\text { Number of } \\
\text { mutations }\end{array}$ & $\begin{array}{c}\text { Hazard } \\
\text { ratio }\end{array}$ & $\begin{array}{c}95 \% \mathrm{Cl} \\
\text { lower }\end{array}$ & $\begin{array}{c}95 \% \mathrm{Cl} \\
\text { upper }\end{array}$ & $P$ value \\
\hline L2 & 6 & 1.80 & 0.66 & 4.90 & .247 \\
L3 & 82 & 2.04 & 1.45 & 2.85 & $<.001$ \\
Non-L3 & 43 & 1.56 & 0.99 & 2.48 & .053 \\
S4 & 13 & 3.38 & 1.74 & 6.57 & $<.001$ \\
Non-S4 & 112 & 1.76 & 1.28 & 2.41 & $<.001$ \\
Disruptive & 90 & 1.85 & 1.32 & 2.58 & $<.001$ \\
Nondisruptive & 36 & 1.62 & 1.00 & 2.64 & .048 \\
\hline
\end{tabular}

Supplementary Table 4. Fisher Exact Test for the Selected Clinical Features and TP53 Mutations in Chinese Cohort

\begin{tabular}{|c|c|c|c|c|c|c|}
\hline & Mutation type & Wild type & Odds ratio & $95 \% \mathrm{Cl}$ lower & 95\% Cl upper & $P$ value \\
\hline \multicolumn{7}{|l|}{ Mutation, any type } \\
\hline Sex (male/female) & $112 / 13$ & $170 / 35$ & 1.77 & 0.87 & 3.82 & .109 \\
\hline Age $(<50 / \geq 50, y)$ & $73 / 52$ & $100 / 105$ & 1.47 & 0.92 & 2.37 & .112 \\
\hline AFP $(\geq 300 /<300 \mathrm{ng} / \mathrm{mL})$ & $74 / 48$ & $96 / 104$ & 1.67 & 1.03 & 2.71 & .029 \\
\hline Size $(\geq 5 /<5 \mathrm{~cm})$ & $73 / 51$ & $104 / 101$ & 1.39 & 0.86 & 2.24 & .171 \\
\hline Presence of cirrhosis (yes/no) & $86 / 38$ & $163 / 42$ & 0.58 & 0.34 & 1.01 & .046 \\
\hline Grade (III, IV/I, II) & $71 / 42$ & $113 / 66$ & 0.99 & 0.59 & 1.66 & 1.000 \\
\hline $\operatorname{HBV}(+/-)$ & $106 / 19$ & $190 / 19$ & 0.56 & 0.27 & 1.17 & .109 \\
\hline $\operatorname{HCV}(+/-)$ & $2 / 123$ & $3 / 206$ & 1.12 & 0.09 & 9.89 & 1.000 \\
\hline \multicolumn{7}{|l|}{ Hot spot mutations } \\
\hline Sex (male/female) & $76 / 8$ & $170 / 35$ & 1.95 & 0.84 & 5.11 & .144 \\
\hline Age $(<50 / \geq 50, y)$ & $54 / 30$ & $100 / 105$ & 1.86 & 1.09 & 3.32 & .019 \\
\hline $\operatorname{AFP}(\geq 300 /<300 \mathrm{ng} / \mathrm{mL})$ & $47 / 34$ & $96 / 104$ & 1.50 & 0.86 & 2.61 & .148 \\
\hline Size $(\geq 5 /<5 \mathrm{~cm})$ & $48 / 35$ & $104 / 101$ & 1.33 & 0.77 & 2.31 & .299 \\
\hline Presence of cirrhosis (yes/no) & $53 / 30$ & $163 / 42$ & 0.46 & 0.25 & 0.83 & .007 \\
\hline Grade (III, IV/I, II) & $53 / 26$ & $113 / 66$ & 1.19 & 0.66 & 2.18 & .575 \\
\hline $\operatorname{HBV}(+/-)$ & $71 / 13$ & $190 / 19$ & 0.55 & 0.24 & 1.27 & .146 \\
\hline $\operatorname{HCV}(+/-)$ & $0 / 84$ & 3/206 & 0.00 & 0.00 & 6.04 & .560 \\
\hline
\end{tabular}


A

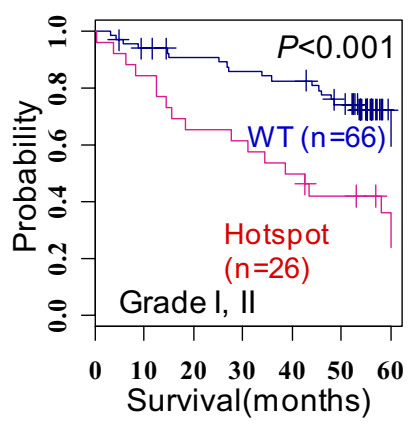

C

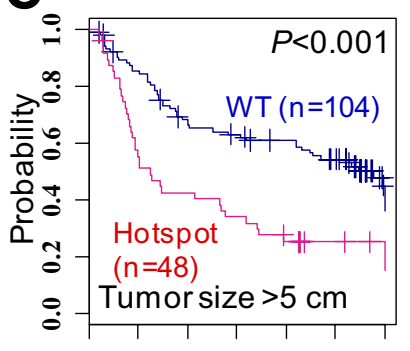

$\begin{array}{lllllll}0 & 10 & 20 & 30 & 40 & 50 & 60\end{array}$ Survival(months)
B

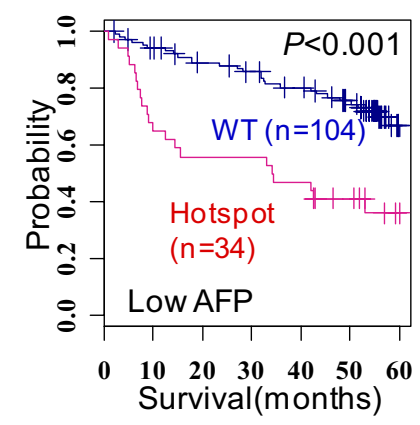

D

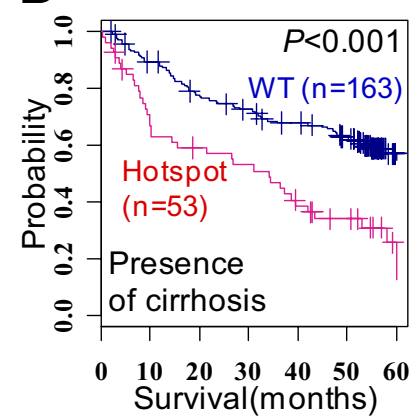

Supplementary Figure 1. Prognostic values of TP53 mutations in patients who have several clinical features. $(A-D)$ Kaplan-Meier plot for survival between patients with hot spot mutated and wild-type TP53 in the subpopulations of patients who have low tumor grade (I, II; $A$ ), low serum AFP level (<300 $\mathrm{ng} / \mathrm{mL} ; B)$, large tumor size $(>5 \mathrm{~cm}$; $C)$, or cirrhosis (D). WT indicates wild-type TP53. 
A

\section{MT WT Chinese Caucasian}
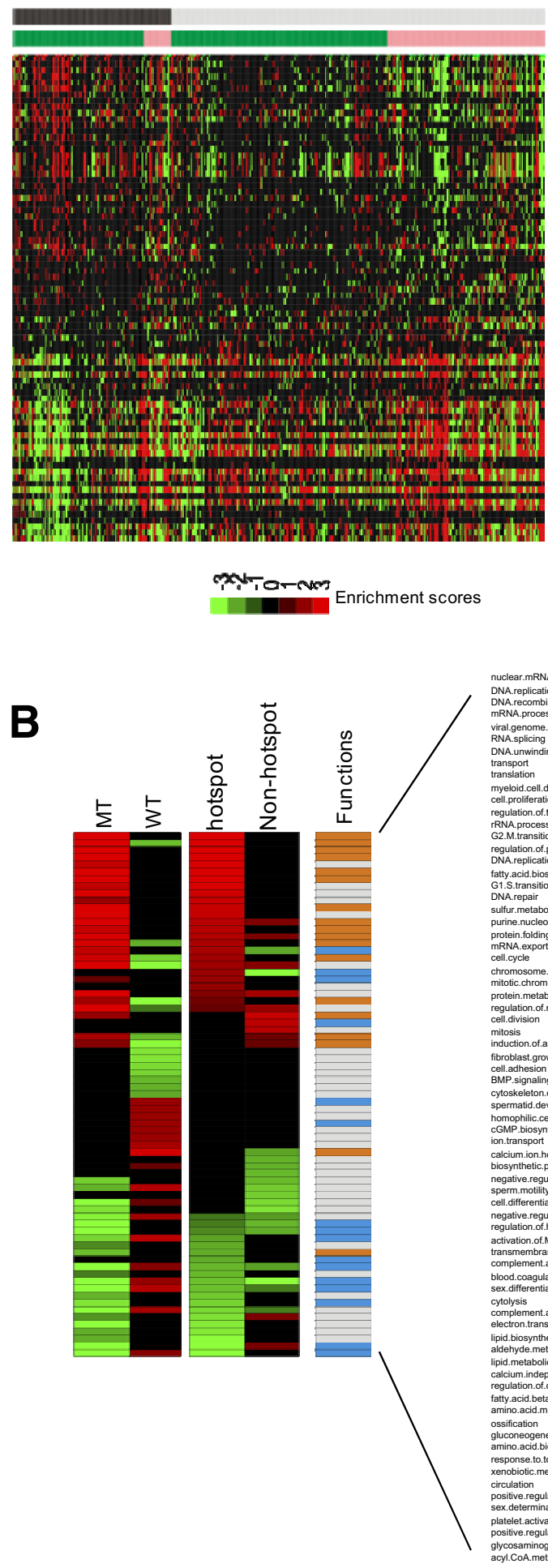
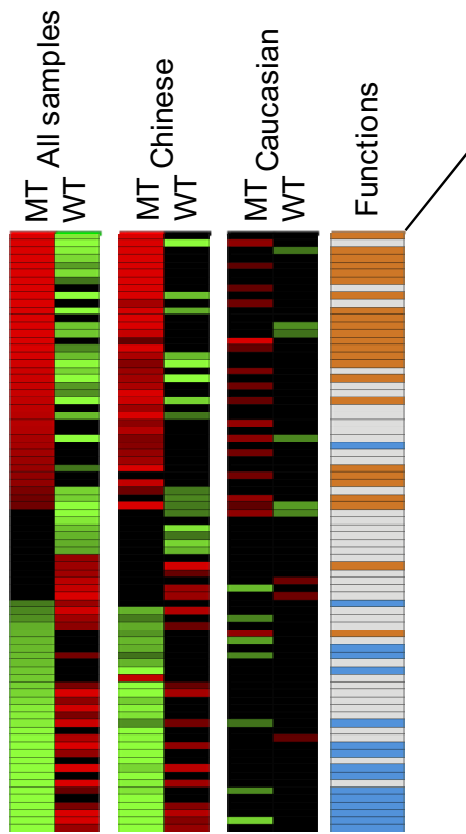

Proliferation Metabolism Unclassified
DNA.repair

RNA.splicing

DNA.unwinding.during.replication

mRNA.processing

mRNA. export.rossion.through.cell.cycle

regulation of tram.nucle

DNA.replication.initiation

intracellular.protein.transport

DNA.replication

rRNA.processing

.

regulation. of.transcription from.RNA. polymerase.II.promoter DNA recombination

cell.division

mitosis

protein.import.into.nucleus..docking

G1.S.transition.of.mitotic.cell.cycle

protein.complex.assembly

chromosome.segregation

small.GTPase.mediated signal transduction

mRNA.transport

DNA.metabolic.process

NLS.bearing.substrate.import.into.nucleus

cell.proliferation

transcription

viral.genome.replication

unfolded.protein.respons

RNA. processing

positive.regulation.of.epithelial.cell.proliferation

proten.impotion on

pathway

政

BMP.signaling.pathway

cytoskeleton.organization.and.biogenesis

iron.ion.homeostasis

negative.regulation.of.cell.proliferatio

protein.localization

protein.localization
calcium.ion.homeostasis

negative.regulation of angiogenesis

fatty.acid.beta.oxidation

blood.coagulation

pathogenesis

lipid.transport

positive.regulation.of.cell.proliferation

folic acid and

ve.biosynthetic.process

superoxide.metabolic. process

response.to.toxi

aldehyde.metabolic.process

transport

cytolysis

complement.activation...classical.pathway

proteolysis

probelysis

fatty.acid.metabolic.process

sex.determination

iron.ion.transport

metabolic.process

choid.metabolic.process

lipid.metabolic.process

glycosaminoglycan.metabolic.process

electron.transport

xenobiotic.metabolic.process

lipid.biosynthetic.process

acyl.CoA.metabolic.process

amino.acid.biosynthetic.process

gluconeogenesis

Supplementary Figure 2. Gene set enrichment of TP53 mutated and wild-type HCC. (A) The functional enrichment scores in the Gene Ontology (GO) hierarchy for each sample were calculated using hypergeometric test with threshold of $P<.01$ in the $366 \mathrm{HCC}$ data set. A total of $80 \mathrm{GO}$ terms were significantly enriched at least in the mutation-type (MT) or wild-type (WT) group $(P<.01$, hypergeometric test) in the samples, Chinese, or white groups (right bars). ( $B$ In the Chinese cohort $(n=238)$, the enrichment scores in each group of hot spot, non-hot spot, and wild-type were calculated. A total of 73 GO terms were significantly enriched at least in 1 group (right). The GO terms with less than 10 genes or the GO terms enriched with less than $10 \%$ of samples were excluded in each analysis. The GO terms of proliferation/cell cycle- and metabolism-related functions were indicated with different colors (right bar). 

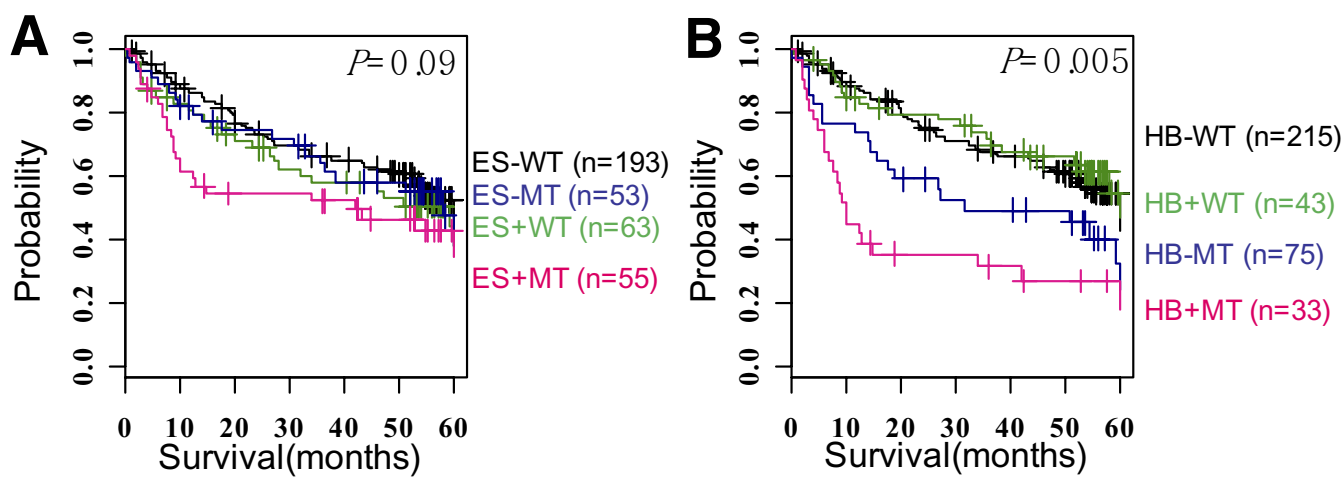

Supplementary Figure 3. Kaplan-Meier plot analysis of survival with TP53 mutation status and stemness-related signatures. (A and $B)$. Based on the status of expression of embryonic stem (ES) $1(A)$ and hepatoblast (HB) $(B)$ signatures and TP53 mutations, the 366 patients were stratified into 4 groups. ES + represent the tumors that were enriched with ES1 signature $(P<.01)$, whereas other tumors were indicated as ES-. HB+ represents the tumors that were positively enriched with HB_UP and negatively enriched with HB_DOWN signatures $(P<.01)$, whereas other tumors were indicated as $\mathrm{HB}-$.

Supplementary Table 5. Gene Set Enrichment Analysis of Embryonic Stem Cell-Related Genes in TP53 Mutated Breast and Lung Cancers

\begin{tabular}{|c|c|c|c|c|c|}
\hline Signatures & Size $(n)$ & Enrichment score & Normalized enrichment score & Nominal $P$ value & False discovery rate \\
\hline \multicolumn{6}{|l|}{ Breast cancer } \\
\hline ES1 & 336 & 0.566 & 2.650 & 0 & 0 \\
\hline ES2 & 38 & 0.652 & 2.181 & 0 & 0 \\
\hline MYC2 & 749 & 0.381 & 1.911 & 0 & $1.83 \times 10^{-4}$ \\
\hline MYC1 & 218 & 0.397 & 1.784 & 0 & $4.47 \times 10^{-4}$ \\
\hline sox2 & 607 & 0.278 & 1.370 & $1.20 \times 10^{-3}$ & $2.27 \times 10^{-2}$ \\
\hline NANOG & 810 & 0.272 & 1.358 & $1.14 \times 10^{-3}$ & $2.19 \times 10^{-2}$ \\
\hline Oct4 & 247 & 0.200 & 0.911 & $6.96 \times 10^{-1}$ & $8.07 \times 10^{-1}$ \\
\hline NOS & 147 & 0.207 & 0.886 & $7.29 \times 10^{-1}$ & $8.03 \times 10^{-1}$ \\
\hline \multicolumn{6}{|l|}{ Lung cancer } \\
\hline ES1 & 356 & 0.585 & 2.889 & 0 & 0 \\
\hline ES2 & 37 & 0.623 & 2.225 & 0 & 0 \\
\hline MYC2 & 757 & 0.416 & 2.150 & 0 & 0 \\
\hline NANOG & 911 & 0.349 & 1.838 & 0 & 0 \\
\hline sox2 & 677 & 0.353 & 1.820 & 0 & $9.82 \times 10^{-5}$ \\
\hline Oct4 & 275 & 0.330 & 1.590 & 0 & $1.99 \times 10 \mathrm{E}^{-3}$ \\
\hline MYC1 & 219 & 0.293 & 1.378 & $1.67 \times 10^{-2}$ & $1.64 \times 10^{-2}$ \\
\hline NOS & 171 & 0.287 & 1.306 & $4.82 \times 10^{-2}$ & $2.91 \times 10^{-2}$ \\
\hline
\end{tabular}


Supplementary Table 6. Differentially Overexpressed Genes in TP53 Mutated Tumors Compared With Wild-Type Tumors

\begin{tabular}{|c|c|c|c|c|c|c|c|}
\hline Gene ID & Symbol & $\begin{array}{l}P \text { value } \\
(t \text { test })\end{array}$ & $\begin{array}{c}P \text { value } \\
\text { (permuted } t \text { test) }\end{array}$ & $\begin{array}{l}\text { False discovery } \\
\text { rate }\end{array}$ & $\begin{array}{l}\text { Average } \\
\text { (MT) }\end{array}$ & $\begin{array}{l}\text { Average } \\
\text { (WT) }\end{array}$ & $\begin{array}{l}\text { Fold difference } \\
\quad \text { (unlogged) }\end{array}$ \\
\hline 934 & CD24 & .0005 & .0016 & 0.0522 & 2.18 & -0.71 & 7.44 \\
\hline 157273 & LOC157273 & .0079 & .0006 & 0.0296 & 1.49 & -0.19 & 3.19 \\
\hline 23089 & PEG10 & .0006 & .0008 & 0.0353 & 1.18 & -0.35 & 2.89 \\
\hline 6690 & SPINK1 & .0013 & .0031 & 0.0777 & 1.17 & -0.35 & 2.87 \\
\hline 154754 & TRY6 & .0011 & .0001 & 0.0126 & 1.21 & -0.10 & 2.48 \\
\hline 6066 & RNU2 & .0160 & .0014 & 0.0491 & 0.99 & -0.22 & 2.31 \\
\hline 174 & AFP & .0026 & .0020 & 0.0606 & 0.77 & -0.34 & 2.16 \\
\hline 4100 & MAGEA1 & .0042 & .0029 & 0.0753 & 0.94 & -0.17 & 2.16 \\
\hline 6364 & CCL20 & .0003 & .0007 & 0.0341 & 0.79 & -0.32 & 2.16 \\
\hline 1047 & CLGN & .0036 & .0030 & 0.0760 & 0.80 & -0.25 & 2.07 \\
\hline 388677 & NOTCH2NL & .0022 & .0016 & 0.0526 & 0.85 & -0.18 & 2.04 \\
\hline 8364 & HIST1H4C & .0000 & .0000 & 0.0000 & 0.71 & -0.31 & 2.02 \\
\hline 259266 & ASPM & .0000 & .0008 & 0.0348 & 0.76 & -0.25 & 2.01 \\
\hline 3248 & HPGD & .0016 & .0047 & 0.0994 & 0.86 & -0.14 & 2.00 \\
\hline
\end{tabular}

MT, mutant type; WT, wild type. 